THE CONDENSATION OF CHLORAL WITH RESORCINOL. 1265

LXXI.-The Condensation of Chloral with Resorcinol. By J. T. Hewit', M.A., D.Sc., Ph.D., and Frank G. Pope.

A Bovt six years ago the action of chloral on resorcinol in the presence of a condensing agent in aqueous solution was stadied by $\mathrm{H}$. Causse (Bull. Soc. Chim., 1890, [3], 3, 861), who obtained by this means a compound to which he assigned the formula $\mathrm{C}_{14} \mathrm{H}_{12} \mathrm{O}_{6}$. His method of procedure consisted in dissolving 100 grams of resorcinol and 20 grams of hydrogen sodium sulphate in 1 litre of water, adding 50 grams of chloral hydrate, and allowing the mixture to stand for some time, when colourless crystals were obtained, which, on heating, lost a molecule of water, and were converted into a yellow substance,

VOL. LXIX. 
$\mathrm{C}_{14} \mathrm{H}_{10} \mathrm{O}_{5}$. The latter was also deposited on heating the solution in the first place instead of allowing it to remain at the ordinary temperature. Causse also obtained the compound $\mathrm{C}_{14} \mathrm{H}_{12} \mathrm{O}_{6}$ by the condensation of resorcinol with glyoxylic acid, and concluded that it was formed according to the equation

$\mathrm{CCl}_{3} \cdot \mathrm{CH}(\mathrm{OH})_{2}+2 \mathrm{C}_{6} \mathrm{H}_{4}(\mathrm{OH})_{2}=\left(\mathrm{OH} \cdot \mathrm{C}_{6} \mathrm{H}_{4} \mathrm{O}\right)_{2} \mathrm{CH} \cdot \mathrm{COOH}+3 \mathrm{HCl}$.

The anhydride would then have the formula

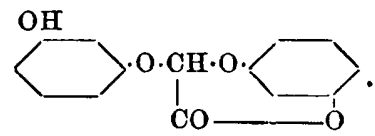

This looks improbable, as the lactone ring would consist of a 7-membered chain, and, moreover, it would involve ring closing in the case of meta-substituents.

Causse further stated that the compound of the formula $\mathrm{C}_{14} \mathrm{H}_{12} \mathrm{O}_{6}$ yielded a diacetyl derivative of the formula. $\mathrm{C}_{14} \mathrm{H}_{10} \mathrm{O}_{6}\left(\mathrm{CO} \cdot \mathrm{CH}_{3}\right)_{2}$ when heated with acetic anhydride, and that this melted and decomposed at $252^{\circ}$.

Some time afterwards, Möhlau, in studying the reaction of various aldehydes with resorcinol, showed that usually the reaction followed the course indicated by the equation

$$
2 \mathrm{C}_{6} \mathrm{H}_{4}(\mathrm{OH})_{2}+\mathrm{R} \cdot \mathrm{CHO}=\mathrm{H}_{2} \mathrm{O}+\mathrm{R} \cdot \mathrm{CH}\left[\mathrm{C}_{6} \mathrm{H}_{3}(\mathrm{OH})_{2}\right]_{2} \text {. }
$$

The tetrahydroxydiphenylmethane derivatives produced undergo further condensation and also oxidation, when subjected to the action of concentrated sulphuric acid, hydroxyfluorones being obtained.

$$
\mathrm{R} \cdot \mathrm{CH}\left[\mathrm{C}_{6} \mathrm{H}_{3}(\mathrm{OH})_{2}\right]_{2}+\mathrm{O}=2 \mathrm{H}_{2} \mathrm{O}+\mathrm{R} \cdot \mathrm{C} / \mathrm{C}_{\mathrm{C}_{6} \mathrm{H}_{3} \cdot \mathrm{OH}}^{\mathrm{C}_{6} \mathrm{H}_{3} \cdot \mathrm{O}} \stackrel{\mathrm{O}}{>} .
$$

However, Möhlau did not examine the action of chloral, and as it seemed possible that we might be able to obtain a hydroxyfluoronecarboxylic acid, $\underset{\mathrm{HO} \cdot \mathrm{C}_{6} \mathrm{H}_{3}}{\mathrm{O}: \mathrm{C}_{6} \mathrm{H}_{3}} \mathrm{C} \cdot \mathrm{COOH}$, we determined to reinvestigate the reaction.

We dissolved 100 grams of resorcinol, 50 grams of chloral hydrate, and 20 grams of hydrogen potassium sulphate in a litre of water and allowed the solution to stand for one month. Only a trace of crystal. line matter separated; it should be mentioned that we were working during January, and that precautions were taken to prevent evaporation of the solution. We, therefore, heated the mixture on a water bath, taking about 12 hours to evaporate the solution to half its volume; it became darker in colour, and a considerable quantity of 
yellow rosettes of needles separated, which were collected, well washed with water, and dried. The mother liquor gave a second crop on further evaporation. By recrystallisation from alcohol, the substance was obtained colourless, and gave numbers which agreed with the formula $\mathrm{C}_{11} \mathrm{H}_{10} \mathrm{O}_{5}$.

\begin{tabular}{|c|c|c|c|}
\hline \multirow[b]{3}{*}{ C } & \multirow{2}{*}{$\begin{array}{l}\text { Calculated for } \\
\mathrm{C}_{14} \mathrm{~B}_{10} \mathrm{O}_{5} \text {. }\end{array}$} & \multicolumn{2}{|c|}{ Found. } \\
\hline & & I. & Ir \\
\hline & . $\quad 65 \cdot 12$ & 6466 & 65.07 \\
\hline $\mathrm{H}$ & $3 \cdot 87$ & $4 \cdot 68$ & - \\
\hline
\end{tabular}

As will be seen later, this substance is the lactone of an acid of the formula $\mathrm{C}_{14} \mathrm{H}_{12} \mathrm{O}_{6}$. It was of interest to see whether it was capable of losing a further quantity of water, giving perhaps a compound $\mathrm{C}_{14} \mathrm{H}_{8} \mathrm{O}_{4}$. We found, in agreement with Causse's statement, that the compound suffers some decomposition at $250^{\circ}$, being transformed into a dark-coloured mass, soluble, however, in alkalis with a brownish-red colour. To aroid this change we heated it in a stream of coal gas at a temperature of $190-200^{\circ}$, although we accidentally allowed the temperature to rise to $225^{\circ}$ for a few minutes. This heating was continued for eight hours, and that it had effected no change beyond a slight darkening, was proved by a combustion, $\mathrm{C}=$ $65 \cdot 36 ; \mathrm{H}=3.95$ per cent. The compound contains three hydroxygroups, as was shown by its conversion into an

Acetyl Derivative.-This was effected by boiling it for two hours, with an excess of acetic anhydride, in a flask provided with a reflux tube; the contents were then poured into cold water, and, after some time, set to a crystalline mass, which was collected, washed, and recrystallised from acetic acid. Glittering, colourless leaflets were obtained, which melted at $149-152^{\circ}$. After recrystallisation from 50 per cent. acetic acid, the melting point was obserred at $152^{\circ}$, exactly $100^{\circ}$ lower tban the temperature given by Causse for the melting point of his diacetate.

$$
\begin{aligned}
& \text { Calculated for } \\
& \mathrm{C}_{14} \mathrm{H}_{7} \mathrm{O}_{5}\left(\mathrm{COCH}_{3}\right)_{3} \text {. Found. } \\
& \text { C . ......... } 62 \cdot 50 \quad 6222 \\
& \text { H......... } 4 \cdot 17 \quad 4: 31
\end{aligned}
$$

The acetate is insoluble in water and light petroleum, sparingly soluble in ether, alcohol, and toluene, soluble in glacial acetic acid, ehloroform, and acetone.

The behaviour of the substance of the composition $\mathrm{C}_{14} \mathrm{H}_{10} \mathrm{O}_{5}$ towards bases is of great interest. With cold ammonia, or sodium hydroxide solutions, a magnificent purple solution is obtained, closely resembling the alkaline solution of phenolphthalein, but is of a slightly bluer shade. If, however, the alkaline solution be gently 


\section{THE CONDENSATION OF CHLORAL WITH RESORCINOL.}

warmed, the colour changes to orange, and the solution exhibits a brilliant green fluorescence. We are inclined to attribute this colour and fluorescence to slight oxidation, for if a pale orange ammoniacal solution, obtained in this way, be treated with a mere trace of zinc dust, the colour is completely discbarged, whilst, on the other hand, the colour can be changed from pale orange to a very deep brown by drawing a current of air through the solution.

On adding an acid to the purple alkaline solntion, the substance is reprecipitated unchanged, whilst, on the other hand, moderately concentrated solutions which have been warmed, and from which the purple colour has been removed, give no precipitate when acidified.

The ammoniacal solution, from which excess of ammonia had been removed by continued boiling, gave no precipitates with most metallic solutions, but with lead acetate a faint precipitate was obtained. This was filtered off, and by the addition of a few drops of ammonia to the filtrate, a pink, floceulent precipitate was obtained, which was collected, thoroughly washed, and dried at $100^{\circ}$; at higher temperatures this compound was found to become first dark blue, and fiually brown. A lead estimation was made, the percentage of metal being found to be $66 \cdot 18$. A basic salt of the formula $\mathrm{C}_{14} \mathrm{H}_{12} \mathrm{O}_{6}, 3 \mathrm{PbO}$ would require 65.71 per cent. of lead.

Barium Salt, $\mathrm{Ba}\left(\mathrm{C}_{14} \mathrm{H}_{11} \mathrm{O}_{6}\right)_{2}$.- As salts of the acid could not be obtained by precipitation, on account of their solubility in water, we prepared the barium salt by boiling 1 gram of the lactone with 1 gram (an excess) of barium carbonate and 50 c.c. of water. The lactone passed slowly but completely into solution, carbon dioxide escaping. The hot filtered solution, which was orange coloured, owing to unavoidable oxidation, was concentrated, the residue thoroughly dried, and a barinm estimation made.

$$
\begin{aligned}
& \text { Calculated for } \\
& \mathrm{Ba}\left(\mathrm{C}_{14} \mathrm{H}_{11} \mathrm{O}_{6}\right)_{2} \text {. Found. } \\
& \text { Ba...... } 19 \cdot 94 \quad 19 \cdot 43
\end{aligned}
$$

The compounds $\mathrm{C}_{14} \mathrm{H}_{12} \mathrm{O}_{6}$ and $\mathrm{C}_{14} \mathrm{H}_{10} \mathrm{O}_{5}$ are thus seen to stand to one another in the relation of acid to lactone, the former easily soluble in water, the latter insoluble. Solations of the salts of the acid give no precipitate in the cold when acidified, but, if the solution is heated, the lactone crystallises out; the purple solution gives, however, an immediate precipitate of the lactone on acidification. From the result obtained on acetylation, it follows that the lactone still possesses three phenolic hydroxyl groups, and consequently the acid must have four, and is to be regarded as a tetrahydroxydiphenylacetic acid. The equation representing its formation will consequently be

$2 \mathrm{C}_{6} \mathrm{H}_{4}(\mathrm{OH})_{2}+\mathrm{CH}(\mathrm{OH})_{2} \cdot \mathrm{CCl}_{3}=3 \mathrm{HCl}+\left[\mathrm{C}_{6} \mathrm{H}_{3}\left(\mathrm{OH}_{2}\right)\right]_{2} \mathrm{CH} \cdot \mathrm{COOH}$. 
DOUBLE SULPHIDES OF GOLD AND OTHER METALS. 1269

Probably the constitutional formula is to be represented by I. This would explain the very ready formation of the lactone II-

I.<smiles>O=C(O)C(C1CCOCC1)C(O)C1CCOCC1</smiles>

II.<smiles>O=C1OC2CC(O)CCC2C1C(O)CCO</smiles>

and also show why the latter does not pass over into a derivative of diphenylenemethane oxide on heating to $200^{\circ}$.

We must reserve our views as to the strongly coloured alkaline solution of the lactone for a future communication.

East London Technical College, People's Palace, London, $E$. 